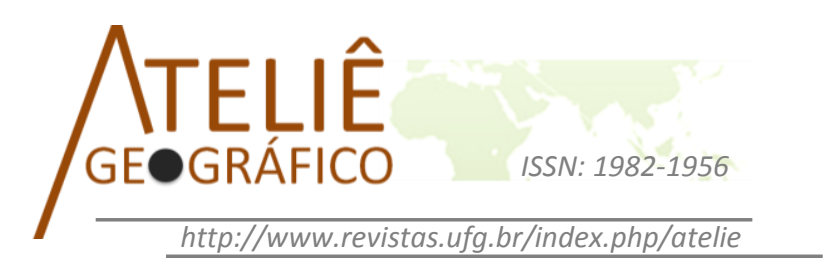

\title{
O Desenvolvimento Rural no Brasil e em Portugal: os casos do Programa de Microbacias em São Paulo e da Iniciativa Leader em Portugal
}

\author{
The Rural Development in Brazil and in Portugal: the cases of \\ the 'Program For Sub-basins' in Sao Paulo, and the \\ 'Initiative Leader' in Portugal \\ El Desarrollo Rural en Brasil y Portugal: los casos de lo \\ Programa de Cuencas Hidrográficas en São Paulo y de la \\ Iniciativa Leader en Portugal
}

\author{
Carlos de Castro Neves Neto \\ Universidade Estadual Paulista - Campus de Presidente Prudente \\ netosulian@gmail.com \\ Antonio Nivaldo Hespanhol \\ Universidade Estadual Paulista - Campus de Presidente Prudente \\ nhespanhol@gmail.com
}

\begin{abstract}
Resumo
No artigo são analisadas as experiências de desenvolvimento rural implementadas no Estado de São Paulo, por meio do Programa de Microbacias Hidrográficas, e em Portugal, por meio do Programa Ligações Entre Ações de Desenvolvimento da Economia Rural (LEADER). Não obstante suas diferenças geográficas e históricas, Brasil e Portugal possuem políticas específicas para as áreas rurais que apresentam similitudes. A iniciativa LEADER em Portugal é financiada, principalmente, pela União Europeia, e busca promover a revitalização dos espaços rurais ao incentivar o estabelecimento de empreendimentos não-agrícolas em freguesias, destacando dentre elas as atividades ligadas ao turismo. No Estado de São Paulo, desde 2000, vem sendo executado o Progama de Microbacias, o qual tem por objetivo promover o desenvolvimento rural sustentável. Esse progama, em sua primeira edição, teve como foco principal a recuperação dos recursos naturais e na sua segunda edição, iniciada no ano de 2011, passou a conceder recursos a fundo perdido para financiar planos de
\end{abstract}


negócios, vinculados a cadeias produtivas específicas desenvolvidas por associações de produtores rurais e cooperativas.

Palavras-chave: LEADER, Programa de Microbacias, Desenvolvimento rural, Espaços rurais.

\begin{abstract}
This article analyzes the experiences of rural development implemented in the State of Sao Paulo through the 'Program for Sub-basins', and in Portugal, through the Program Links Intertwined with Actions for the Development of Rural Economy (LEADER). Despite their geographical and historical differences, Brazil and Portugal have specific policies for rural areas that hold similarities. The LEADER initiative in Portugal is mainly financed by the European Union, and it seeks to promote the revitalization of rural spaces as the means to encourage the establishment of nonagricultural enterprises in villages, among them tourism has had special attention. In the State of Sao Paulo, since 2000, the Program for Sub-basins has been implemented, and it aims to promote a sustainable rural development. In its first edition, the Program had as main focus the recovery of natural resources, and for its second edition, which started in 2011, it was used available outright grants funds to finance business plans linked to specific production networks developed by Rural Producers and Cooperatives Associations.
\end{abstract}

Keywords: LEADER, Program for Sub-basins, Rural Development, Rural Areas.

\begin{abstract}
Resumen
En el artículo se analizan las experiencias de desarrollo rural en el Estado de São Paulo, a través del Programa de Microcuencas, y en Portugal, a través del Programa vínculos entre acciones para el Desarrollo de la economía rural (LEADER). A pesar de las diferencias geográficas e históricas, Brasil y Portugal cuentan con políticas específicas para las zonas rurales que tienen similitudes. La iniciativa LEADER en Portugal está financiado principalmente por la Unión Europea, con el objetivo de promover la revitalización de los espacios rurales para fomentar la creación de empresas no agrícolas en las parroquias, destacando entre ellas las actividades relacionadas con el turismo. En el Estado de São Paulo, desde el año 2000, está en ejecución el Programa de Cuencas Hidrográficas, que apunta a promover el desarrollo rural sostenible. Este programa, en su primera edición, ha tenido como principal objetivo la recuperación de los recursos naturales y en su segunda edición, se inició en el año 2011, fuimos a conceder a los recursos a fondo perdido para financiar planes de negocios específicos, vinculados a las cadenas de producción desarrollados por las asociaciones de productores rurales y cooperativas.
\end{abstract}

Palabras clave: LEADER, Programa de Cuencas Hidrográficas, desarrollo rural, espacios rurales.

\title{
Introdução
}

Não obstante as diferenças territoriais entre Brasil $\left(8.516 .000 \mathrm{~km}^{2}\right)$ e Portugal $\left(92.340 \mathrm{~km}^{2}\right)$, os dois países têm se preocupado com os seus respectivos espaços rurais e possuem políticas específicas para atender a população que vive nessas áreas.

No presente artigo analisaremos duas importantes políticas de desenvolvimento rural (Programa de Microbacias e LEADER) que esses países 
têm implementado nos últimos anos. Analisaremos o surgimento da Política Agrícola Comum (PAC) no contexto da formação da União Europeia e, em seguida, apresentaremos os objetivos da PAC, as suas reformas e resultados até a instituição do Programa LEADER no início dos anos 1990, que passou a fomentar o desenvolvimento rural a partir da atuação dos Grupos de Ação Locais (GALs). Também discorreremos sobre as três edições do Programa LEADER até a sua conversão num dos eixos estruturais do Fundo Agrícola de Desenvolvimento Rural (FEADER), sendo, no caso de Portugal, incorporado ao Programa de Desenvolvimento Rural - PRODER.

Ao discorrer sobre as políticas de desenvolvimento rural no Brasil, abordaremos o surgimento do crédito rural com o governo de Getúlio Vargas e a implementação do Sistema Nacional de Crédito Rural em 1965, principal instrumento de política pública utilizado no fomento ao processo de modernização da agricultura. Também, trataremos do Programa Nacional de Fortalecimento da Agricultura Familiar (PRONAF), insitituído em meados dos anos 1990 para atender as demandas específicas dos agricultores familiares, especialmente no que concerne a concessão de crédito rural.

Em âmbito do Estado de São Paulo, analisaremos o Programa de Microbacias, que passou a receber financiamento do Banco Mundial no ano 2000 e, atualmente, está em sua segunda edição. Na primeira edição do Programa Estadual de Microbacias Hidrográficas (2000 - 2008) o foco principal foi recuperar os recursos naturais. Para tanto, o programa disponibilizou recursos financeiros para os produtores rurais e suas associações adquirir implementos agrícolas adequados, implantar terraços e curvas de nível, cercar Áreas de Preservação Permanente, reconstituir matas ciliares, construir abastecedouros comunitários etc.

A atual edição do Programa de Microbacias, iniciada no ano de 2011, recebeu a denominação "Projeto de Desenvolvimento Rural Sustentável Microbacias II - Acesso ao mercado" e se estenderá até o ano de 2015, e tem como principal objetivo o fortalecimento das cadeias produtivas nas quais há grande partipação de agricultores familiares, incentivando-os a ampliar a sua competitividade por intermédio da agregação de valor aos produtos e da inserção no mercado com maior competitividade.

Assim, serão discutidas as mudanças de concepção do Programa de Microbacias da primeira para segunda edição, ressaltando-se o seu caráter excludente. 


\section{A Política Agrícola Comum no contexto da formação da União Europeia}

A política agrícola comum foi lançada em 1962 pela Comunidade Econômica Europeia (CEE), que tinha sido formada em 1957, com o Tratado de Roma. A preocupação do bloco comunitário europeu era garantir a autossuficiência alimentar para a população europeia. Assim, ter uma política comum agrícola foi uma das primeiras preocupações da CEE e todos os Estados-Membros contribuíram financeiramente para a efetivação dessa política. (CARVALHO, 2012).

A PAC teve como objetivos iniciais: elevar a produtividade, melhorar a vida da população rural, estabilizar os mercados e assegurar o abastecimento a preços acessíveis à população. Para financiar essa política foi criado um fundo, em 1962, o Fundo Europeu de Orientação e Garantia Agrícola, sendo o maior orçamento do bloco comunitário. Conforme destaca Cavaco (2005), a preferência comunitária, a solidariedade financeira, permitindo a livre circulação dos produtos dentro dos países membros do bloco caracterizavam os princípios gerais da PAC.

De acordo com Covas (2004), a PAC passou por três grandes períodos, modelos dominantes ou paradigmas: o modelo produtivista tecnológico das décadas de 1960 e 1970, o modelo da contenção-reconversão dos anos 1980 e o paradigma da proteção-conservação da década de 1990 em diante.

A alteração da base técnica agrícola, a produção em grande escala, a especialização produtiva, o êxodo rural acelerado e o excedente na produção de alimentos caracterizaram a primeira fase da PAC. A segunda fase caracterizase pela racionalização e limitação da produção e dos gastos agrícolas. Novas medidas são impostas aos agricultores, como a aposentadoria antecipada, reconversão produtiva e ajudas diretas em dinheiro. A partir dos anos 1990 são realizadas reformas na $\mathrm{PAC}$, as preocupações com o meio ambiente são ampliadas e os espaços rurais deixam de ser identificados somente como o local de desenvolvimento de atividades agrícolas. Fortalece-se a perspectiva do desenvolvimento rural, entendido como aquele que induz a melhoria de vida da população, aliada a conservação dos recursos naturais e culturais. (COVAS, 2004).

Os resultados desta política foram positivos na medida em que a Europa passou a ser autossuficiente em vários produtos, ocorrendo a ampliação do excedente alimentar. No entanto, a PAC se tornou uma política extremamente cara, geradora de desperdício e fomentadora da desigualdade, em virtude de privilegiar os agricultores mais capitalizados e localizados nos países de maior desenvolvimento da União Europeia. Assim, no início dos anos 1990 ocorre a primeira reforma da PAC, que impôs uma série de medidas como quotas de produção, "combinação dos sistemas de preços com as ajudas diretas, 
os controlos diretos de produção, medidas de excepção para as pequenas produções e medidas de acompanhamento." (CARNEIRO, 2004, p. 7). Também se introduz na PAC o princípio da multifuncionalidade, no qual se entende o espaço rural não somente como produtor de alimentos, mas também o espaço de preservação do meio ambiente, de atração do turista, do lazer, do cuidado com o património histórico e cultural e da prática de esportes.

Com a PAC, os países europeus se tornaram autosuficiente na produção de alimentos e, também, passaram a exportar produtos agropecuários. Assim, as reformulações realizadas na PAC a partir dos anos 1990 foram motivadas pelos questionamento da sociedade europeia às subvenções estatais aos setores agropecuários e a pressão externa proveniente dos países exportadores de produtos agrícolas que passaram a denunciar a concorrência desleal exercida pela União Europeia. Mesmo com as reformas, essa política continuou a privilegiar os produtores mais capitalizados, que tinham a sua produção voltada ao mercado externo e o seu custo para a União Europeia continuava alto, já que $90 \%$ das unidades agropecuárias presentes no bloco receberam ajuda financeira do Estado. (ABRAMOVAY, 2002).

Não obstante os custos significativos para a União Europeia, as subvenções aos produtores estão contidas historicamente na cultura e ao sistema produtivo da sociedade europeia, o que dificulta o fim dessa política estatal. A fome provocada pelas duas guerras mundiais no século XX e o grande esforço para a reconstrução no pós-guerra são lembranças que reforçam a importância de uma política específica de segurança alimentar, já que a produção de alimentos é essencial para toda população.

Procurando compreender e atender a multifuncionalidade dos espaços rurais é lançado em 1991 o Programa Ligação Entre Ações de Desenvolvimento da Economia Rural (LEADER), o qual se tornou referência em políticas de desenvolvimento rural na Europa e em outros países. O referido programa estava inserido nas políticas de desenvolvimento rural da PAC (segundo pilar) e foi uma das primeiras iniciativas do bloco europeu com o intuito de fomentar o desenvolvimento local em áreas rurais, com base no financiamento de atividades não agrícolas.

\section{A iniciativa comunitária LEADER}

Com o objetivo de fomentar o desenvolvimento rural sustentável nas zonas rurais europeias, que corresponde a quase $90 \%$ de todo o território, foi lançado o Programa LEADER. O programa foi inovador por incentivar a exploração das potencialidades locais a partir do financiamento de projetos de desenvolvimento elaborados pelos próprios atores locais, sob a coordenação 
dos Grupos de Ação Locais (GAL), com base no reconhecimento do caráter multifuncional e multidimensional dos espaços rurais e na valorização do meio ambiente, da história e da cultura locais, elementos importantes para o desenvolvimento.

O Programa LEADER foi financiado pelo Fundo Europeu de Orientação Agrícola e Desenvolvimento Rural que se constituia no segundo pilar da PAC. Em 2005 o Fundo Europeu de Orientação e Garantia Agrícola (FEOGA) foi substituído pelo Fundo Europeu Agrícola de Desenvolvimento Rural (FEADER), que passou a financiar o LEADER a partir do ano de 2007, quando o LEADER deixou de ser um programa e foi convertido no quarto eixo do FEADER que se volta, especificamente, ao financiamento de atividades não agrícola em ambientes rurais.

O Programa LEADER teve três edições: LEADER I (1991-1993), LEADER II (1994-1999) e LEADER+ (2000-2006). A partir de 2007, a abordagem LEADER foi incorporada nos programas de desenvolvimento rural de cada Estado-Membro da União Europeia, sendo financiado pelo FEADER e pelo orçamento de cada país.

A principal característica da abordagem LEADER é valorizar a diversidade regional, apoiando as iniciativas locais de desenvolvimento rural. São sete as principais características dessa iniciativa comunitária:

a) Estratégias locais de desenvolvimento: Reconhecimento da importância da população local na elaboração, execução e fiscalização das ações, valorizando as especificidades e diversidade de cada área rural europeia;

b) abordagem ascendente: os agentes locais participam das tomadas de decisões, adaptando as ações às necessidades das comunidades atendidas;

c) estabelecimento de parcerias locais entre setores públicos e privados: torna-se fundamental a formação dos Grupos de Ação Local (GAL) que serão os responsáveis por identificar e aplicar uma estratégia de desenvolvimento local, tomar decisões, destinar e gerir os recursos financeiros;

d) facilitar a inovação: seja ao incentivar a introduzir um novo produto, seja na adaptação de inovações tecnológicas;

e) Ações integradas e multissetoriais: por ser uma política de desenvolvimento territorial, a abordagem LEADER deve integrar e fazer parcerias com vários setores da sociedade, com a finalidade de envolver os aspectos econômicos, sociais, culturais e ambientais;

f) Formação de redes institucionais: o objetivo é divulgar os resultados positivos das ações implementadas para que outros países possam aprender e implementar as experiências de sucesso da abordagem LEADER. A partir de 
2007 foi instalada uma rede europeia de desenvolvimento rural, gerida pela comissão e cada Estado-membro instaurou uma rede rural nacional, a fim de divulgar as experiências do LEADER em cada país e lançar projetos de cooperação conjuntos entre os países;

g) Cooperação: existem dois tipos de projetos de cooperação que são geridos por uma estrutura comum. A cooperação interterritorial, aglutinando os Estados-membros de diversas zonas rurais em busca de um projeto comum e a cooperação transnacional, que reúne Grupos de Ação Local de pelo menos dois países da EU com grupos de países terceiros, que tenham iniciativas semelhantes ao

LEADER (http://ec.europa.eu/agriculture/publi/fact/leader/2006_pt.pdf).

As primeiras edições do programa se diferenciaram pelo caráter territorial apresentado, em oposição aos programas setoriais; pelo envolvimento do número de participantes na elaboração, execução e fiscalização dos projetos; na integração de várias políticas públicas, na articulação de membros diversos da sociedade - instituições, empresas, organizações não-governamentais - e no estímulo a criatividade e à valorização dos conhecimentos locais. (FAVARETO, 2007).

As três edições do Programa LEADER demostraram que o desenvolvimento rural pode ser alcançado somente se houver um planejamento adequado de execução de projetos e a participação dos atores e instituições envolvidas, por meio de ações multissetoriais e integradas, incorporando-se a abordagem territorial. São ações bottom-up (de baixo para cima), por contar com o envolvimento dos atores locais na execução dos projetos, diferentemente das ações top-down (de cima para baixo).

Os projetos foram selecionados pelo mérito, não havendo uma préseleção, "como uma maneira de estimular a competição entre territórios e a correspondente mobilização de energias e talentos na busca por estes recursos." (FAVARETO, 2007, p. 131). De acordo com Hespanhol (2007), a gestão dos projetos ficou sob responsabilidade dos Grupos de Ação Locais (GALs), que se encarregaram de formular os projetos e implementá-los.

No período compreendido entre 2000 e 2006 foi implementado o LEADER+, com recursos superiores a dois bilhões de euros, envolvendo mais de mil projetos implantados nos países membros da União Europeia. Nessa edição do programa todos os territórios rurais da U.E puderam acessar os recursos, diferentemente do LEADER I e II, que priorizaram as regiões deprimidas.

Ao estudar o LEADER + na França, Hespanhol (2007) ressalta que esse programa seguiu as orientações da PAC ao incentivar a competitividade e a 
diversificação do desenvolvimento rural, porém com seus próprios métodos de ação. Mas também, o LEADER+ reafirmou os projetos de abordagem territorial, rompendo com o caráter setorial das políticas tradicionalmente direcionadas aos espaços rurais.

$\mathrm{Na}$ tabela 1 constam os valores investidos, a área atendida e a quantidade de grupos formados em cada uma das trêsedições do Programa LEADER. Destacam-se a elevação dos recursos do programa ao longo do período de sua execução (1991-2006) e a extensão da área beneficiada.

Tabela 1: Número de grupos de ação local, área abrangidae valor dos recursos investidos por meio do Programa LEADER

\begin{tabular}{l|l|l|l}
\hline $\begin{array}{l}\text { Programa } \\
\text { LEADER }\end{array}$ & $\begin{array}{l}\text { Número de grupos } \\
\text { de ação local }\end{array}$ & $\begin{array}{l}\text { Superfície } \\
\text { abrangida } \\
\left(\mathrm{km}^{2}\right)\end{array}$ & $\begin{array}{l}\text { Financiamento EU } \\
\text { (milhões de euros) }\end{array}$ \\
\hline LEADER I & 217 & 367000 & 442 \\
\hline LEADER II & 906 & 1375144 & 1.755 \\
\hline LEADER+ & 893 & 1577386 & 2105,1 \\
\hline
\end{tabular}

Fonte: A Abordagem LEADER: um guia básico.

Disponível em: http://ec.europa.eu/agriculture/publi/fact/leader/2006_pt.pdf

Os GALs mobilizaram a população local para se inserirem no programa, assim como acompanharam e fiscalizaram a implementação dos projetos. Cada Gal elaborou uma proposta de desenvolvimento rural buscando aproveitar as potencialidades do território e valorizar a multifuncionalidade dos espaços rurais.

\section{O programa Leader em Portugal e o Proder}

Em Portugal, o Programa LEADER apresentou bom desempenho. Em sua primeira fase de edição atingiu 30 territórios, abrangendo uma área aproximada de $37 \%$ do território português, atendendo $14,3 \%$ da população. $\mathrm{Na}$ segunda edição (LEADER II) beneficiou 33\% da população em 48 territórios (incluindo as ilhas de Madeira e Açores). Na última edição (LEADER+) atingiu $80 \%$ do território, totalizando 52 regiões. Na figura 1, podemos visualizar a evolução do programa LEADER em Portugal em suas três edições. (MORENO, 2005).

Não obstante os resultados alcançados pelo LEADER em Portugal, o programa não beneficiou a parcela da população que vive no rural "profundo", 
ou seja, em áreas pobres, localizadas principalmente no interior do país. Assim, a população com menor nível de organização e menos empreendedora, ficou excluída do LEADER (ROVER; HENRIQUES, 2006).

A necessidade de contrapartida financeira, a cada projeto aprovado pelo LEADER, impediu a participação da população menos capitalizada. A inserção dessa população mais pobre ainda continua sendo um desafio a ser superado pelas políticas de desenvolvimento rural da União Europeia.

De todas as atividades financiadas pelo Programa LEADER, o turismo se destaca com $25 \%$ do total de investimentos, se constituindo na atividade mais importante do programa. Para o desenvolvimento dessa atividade, os Grupos de Ação Local funcionaram como "Agências de Desenvolvimento Local", elaborando iniciativas para fomentar os territórios rurais. Em Portugal $77 \%$ de todo o território recebeu ações de 52 GALs, distribuídos da seguinte forma: oito entre o Douro e o Minho, seis em Trás-os Montes, oito na Beira Litoral, sete na Beira interior, seis no Ribatejo e Oeste, oito no Alentejo, três no Algarve, quatro nos Açores e duas na Madeira. (DINIZ; PANYIK; BREDA, 2011).

O Programa LEADER deixou de existir em 2006, sendo convertido num dos eixos do Fundo Agrícola de Desenvolvimento Rural (FEADER) a partir do ano de 2007, incorporando-se, desde então aos programas nacionais de desenvolvimento rural. No caso de Portugal, a abordagem LEADER foi incorporada ao Programa de Desenvolvimento Rural - PRODER.

Foi estabelecida uma Comissão de acompanhamento da iniciativa LEADER em Portugal, a qual é composta por cem unidades, envolvendo 52 GALs. A Federação Minha Terra - Federação Portuguesa de Associações de Desenvolvimento Local é a principal parceria dos Grupos de Ação Local em Portugal.

A falta de recursos humanos se constitui no principal problema da atuação dos GALs, como revelam Diniz, Panyik e Breda (2011). Esses autores destacam que do total de 1909 projetos apoiados pelo LEADER em Portugal, 778 estavam relacionados ao turismo, o que demonstra a importância dessa atividade como estratégia de desenvolvimento das áreas rurais do país. 


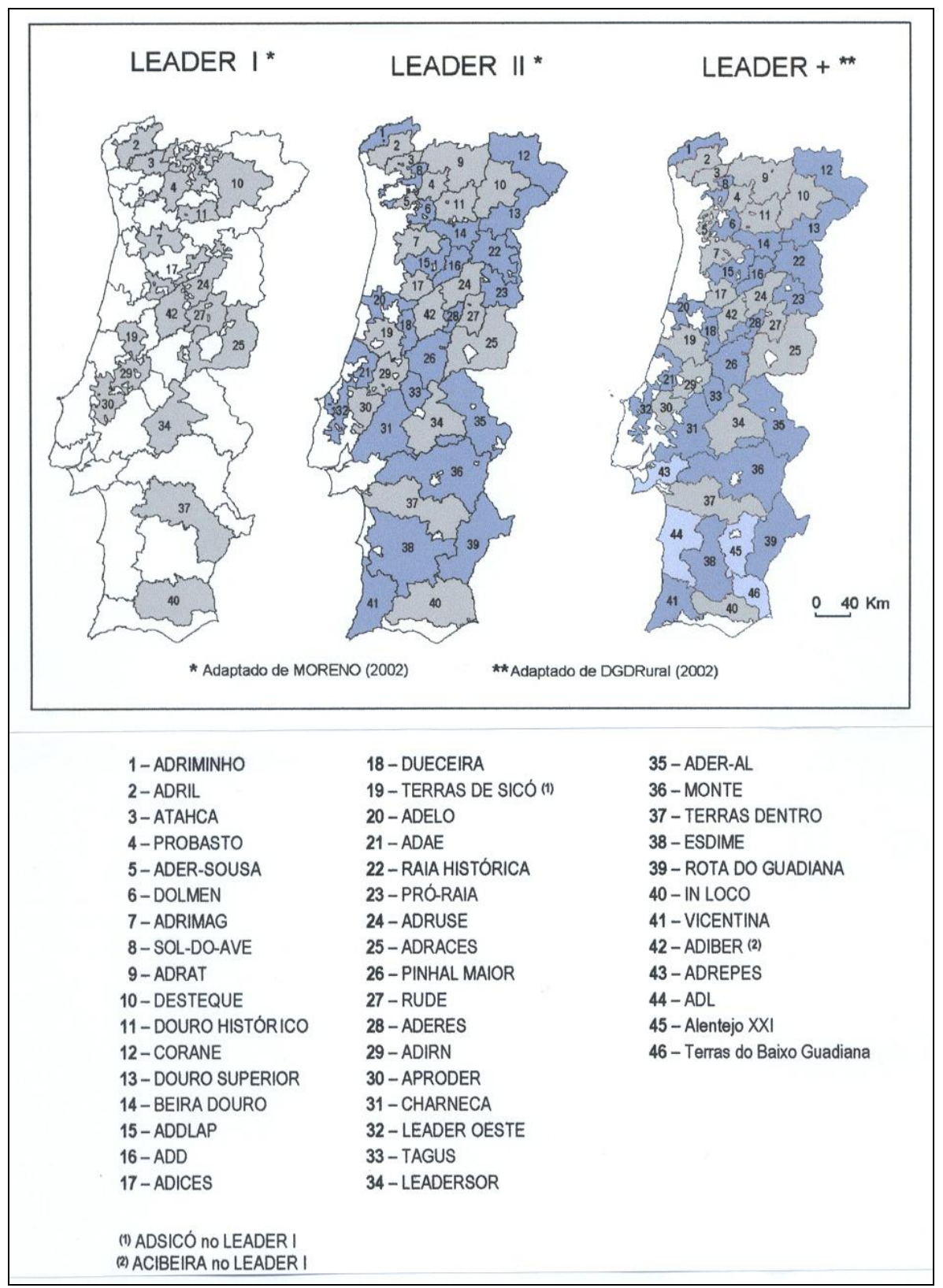

Figura 1: Resultados do Programa LEADER em Portugal.

Fonte: Moreno (2005) 
O PRODER conta contou com recursos da ordem de 3.5 bilhões de euros do Fundo Europeu de Desenvolvimento Regional (FEDER) no decorrer do período 2007 - 2013, estando inserido no Plano Estratégico Nacional. O objetivo principal do programa é elevar a competitividade dos setores agrícola e florestal, promover a sustentabilidade dos espaços rurais e dos recursos naturais e dinamizar econômica e socialmente as zonas rurais.

Batista e Figueiredo (2011) ressaltam que o PRODER prioriza uma boa parte dos seus recursos financeiros para o apoio a atividade agrícola tradicional, sendo a iniciativa LEADER apenas um subcomponente de um subprograma do PRODER.

O PRODER se divide em quatro subprogramas: 1 - Promoção da Competitividade; 2 - Gestão Sustentável dos Espaços Rurais; 3 - Dinamização das zonas rurais e 4 - Promoção do Conhecimento e Desenvolvimento de Competências com carácter transversal.

A abordagem LEADER está inserida no subprograma 3 do PRODER, que visa incentivar ações de desenvolvimento local, por meio dos GALs. Os principais objetivos desse subcomponente 3 é dinamizar economicamente os territórios rurais, por meio da diversificação econômica, criação de empregos e elevação da qualidade de vida da população rural. Também se pretende reforçar a governança local, sendo esta uma característica inovadora da iniciativa IEADER. A meta é atingir 100\% dos territórios rurais portugueses, conforme revela o documento do Programa de Desenvolvimento Rural - Continente2007-2013, publicado em janeiro de 2012. O custo total estimado da iniciativa LEADER em Portugal no período foi de 603.241.74€.

Embora tenha ocorrido avanços ao se incluir o LEADER no PRODER, ainda há o predomínio da distribuição dos recursos para as áreas mais desenvolvidas economicamente e para as atividades agrícolas. Dessa forma, Batista e Figueiredo (2011, p. 289) destacam que "o novo PRODER (...) não tem contribuído para inverter a tendência de esvaziamento social de um extenso território nacional que Baptista (2006) designou como rural de baixa densidade".

\section{O Sistema Nacional de Crédito Rural no contexto das políticas setoriais no Brasil}

A primeira Carteira de Crédito Agrícola no país foi criada em 1937, durante o Governo ditatorial de Getúlio Vargas (1937-1945). Assim, pretendiase elevar a produção agrícola no Brasil, principalmente de alimentos essenciais a população, como o arroz e o feijão. Além da criação do crédito rural, Getúlio Vargas estabeleceu preços mínimos para os produtos básicos da alimentação - 
arroz, feijão, milho, amendoim, soja e girassol. Também no seu governo foram instituídos órgãos para tratar especificamente do fomento de cada cultura agrícola, como o Instituto de Açúcar e Álcool (IAA), o Departamento Nacional do Café (DNC), Superintendência de Desenvolvimento da Borracha. (SUDHEVEA) etc.

Não obstante a atuação do governo de Getúlio Vargas no fomento a agricultura, as ações ainda eram bastante pontuais e a quantidade de recursos destinada aos programas era escassa. No ano de 1965 foi instituido o Sistema Nacional de Crédito Rural (SNCR), com o objetivo de alterar a base técnica da agricultura brasileira, por meio da conversão de parte dos latifúndios em empresas rurais.

Dessa forma, a agricultura incorpora os produtos do pacote tecnológico da "Revolução Verde", tais como máquinas, implementos agrícolas, agrotóxicos, sementes melhoradas etc. $\mathrm{O}$ objetivo principal dos governos militares ao incentivar a modernização da produção agrícola era angariar recursos para financiar o processo de industrialização substitutiva de importações, fornecendo mão de obra excedente para o trabalho nas indústrias. Os recursos a essa política provinham dos financiamentos externos que o país conseguia junto aos países desenvolvidos. Como destaca Hobsbawn (1995), vivíamos a "Era de Ouro" - 1969-1973 - do capitalismo, e os endividamentos dos países subdesenvolvidos como o Brasil era estimulado pelos países desenvolvidos.

O financiamento aos agricultores, por intermédio do SNCR, não foi distribuído de forma equânime, pois atendeu preferencialmente os médios e grandes produtores, principalmente dos Estados de São Paulo, Rio Grande do Sul e Paraná. (GONÇALVES NETO, 1997).

Além do crédito rural, os governos militares instituíram outras medidas para a transformação de latifúndios em empresas rurais integradas às indústrias. Foram criados órgãos de fomento à pesquisa, como, por exemplo, o Instituto de Pesquisa Agropecuário do Oeste (IPEAO), em 1968, e a Empresa Brasileira de Pesquisa Agropecuária (EMBRAPA), no ano de 1973, além de programas específicos de fomento a utilização de insumos, como o Programa Nacional de Fertilizantes e Calcário Agrícola e o Programa Nacional de Defensivos Agrícolas, instituído em 1975. Também se investiu na expansão dos serviços de assistência técnica e extensão rural e foram alocados recursos na implementação da política de garantia de preços mínimos.

Formaram-se no Brasil vários Complexos Agroindustriais (CAIs), o que ampliou a dependência da agricultura em relação as indústrias e ao mercado financeiro. No entanto, a industrialização da agricultura brasileira foi parcial, já que uma pequena parte dos produtores, localizados em regiões 
específicas (Sul e Sudeste) puderam incorporar novas tecnologias à produção agropecuária (SILVA, 1981).

Com essa política restritiva de fomento à produção agropecuária, aumentou-se à polarização na agricultura brasileira. De um lado uma minoria de médios e grandes proprietários que se beneficiaram do crédito abundante a taxas de juros subsidiadas e puderam investir em tecnologia e, consequentemente, aumentar a produção e a produtividade; de outro, a grande maioria dos produtores rurais brasileiros que permaneceram à margem dessa política, mantendo-se com baixa produtividade e vivendo em condições precárias.

De acordo com Silva (1981), o índice de concentração da propriedade da terra no Brasil cresceu continuamente entre os anos de 1965 e 1976. Além do seu valor produtivo, a terra passou a ter um grande valor especulativo, como reserva de valor, fazendo com que milhares de hectares de terras fossem adquiridos na busca de valorização.

Os problemas sociais também se agravaram no decorrer dos governos militares. No período compreendido entre 1960-1980, em torno de 2,5 milhões de pessoas deixaram o espaço rural do Estado de São Paulo, aumentando desenfreadamente a urbanização, principalmente nas grandes cidades. (SILVA, 1999).

Durante os anos 1970 e 1980, o cerrado brasileiro também foi incorporado à produção agrícola e na nova constituição federal promulgada no ano de 1988 foi criado o Fundo Constitucional do Centro-Oeste, por meio do qual o Estado concedeu incentivos financeiros que redundaram na ampliação do desmatamento dos cerrados para o plantio de culturas agrícolas e para a formação de pastagens. O avanço da fronteira agrícola em direção ao cerrado levou a destruição desse bioma, com consequências significativas para a fauna e flora desse importante ecossistema brasileiro. De acordo com Ab'Saber (2003), o cerrado perdeu em torno de $65 \%$ a $70 \%$ de toda a sua vegetação ao longo do século XX.

A modernização da agricultura foi realizada com a manutenção e até aprofundamento do elevado nível de concentração fundiária do país, sendo mantida também a enorme assimetria existente na sociedade brasileira. Os problemas ambientais foram agravados, com a ampliação do desmatamento dos principais biomas, notadamente o Cerrado e a Mata Atlântica e, mais recentemente, a Floresta Amazônica. 


\section{Pronaf: um divisor de águas na política brasileira}

Devido às pressões dos movimentos sociais, como a Confederação Nacional dos Trabalhadores na Agricultura (CONTAG), Movimento dos Trabalhadores Rurais Sem Terra (MST) e Central Única dos Trabalhadores (CUT), o governo Fernando Henrique Cardoso (1995-2002) lança o PRONAF. $\mathrm{O}$ referido programa se constitui num marco para as políticas de desenvolvimento rural no Brasil por permitir o acesso dos chamados agricultores familiares a linhas de créditos com taxas de juros subsidiadas, algo inédito no país.

Além da linha individual do PRONAF, foi lançado um crédito coletivo, denominado PRONAF-Infra Estrutura e Serviços Municipais, por meio do qual eram destinados recursos financeiros para a melhoria da infraestrutura produtiva dos municípios com forte presença de agricultores familiares. Para o acesso a esse crédito, os municípios deveriam ter um Conselho Municipal de Desenvolvimento Rural constituído e dispor de um Plano Municipal de Desenvolvimento Rural.

A criação do PRONAF foi relevante, tanto economicamente, pois uma parcela dos produtores familiares passou a ter acesso ao crédito rural em condições favoráveis, como socialmente, ao ser oficialmente reconhecida a importância desta categoria de produtores. (HESPANHOL, 2010, p. 314).

Em nível institucional se reconhecia a importância da agricultura familiar na produção de alimentos, na diversidade cultural e por sua importância no cuidado com o meio ambiente.

Conforme Souza (2012), o lançamento do PRONAF ocasionou a multiplicação dos CMDR em todo o país, pois era uma exigência para o acesso aos recursos do Pronaf Infra Estrutura e Serviços Municipais. No entanto, como destaca Hespanhol (2010, p. 315), "na maioria dos municípios do país os CMDR são apenas instâncias formais estabelecidas para atender exigências de esferas superiores de poder". Muitos Conselhos sofrem a influência política partidária e muitos os prefeitos impedem que ocorra o debate e o confronto de ideias nos conselhos.

Assim, o não funcionamento efetivo dos CMDRs, o baixo nível de organização e participação dos agricultores familiares, a manipulação dos prefeitos na destinação dos recursos e a reduzida experiência dos técnicos executores que atuam no PRONAF são os principais problemas para o sucesso desse programa (HESPANHOL, 2010).

Entre 1998/1999 e 2008/09 foram efetuados 13,5 milhões de contratos do Pronaf e disponibilizados 55,8 bilhões de reais em recursos. (VELOSO, 2011). No entanto, esse montante beneficiou prioritariamente os produtores 
mais capitalizados e/ou que tinham maior capacidade de endividamento. A grande maioria dos agricultores familiares, pobres, que vivem em condições precárias, foi segregada dessa política pública.

Também no decorrer do governo FHC foi criado, em 1999, o Ministério de Desenvolvimento Agrário, que passou a ser o responsável pela administração do PRONAF, e por outras políticas destinadas aos agricultores familiares, bem como as comunidades tradicionais e aos assentados em projetos de reforma agrária.

Dessa forma, existem no Brasil dois ministérios para tratar das atividades agrícolas. O MDA, responsável pelas políticas de fomento a agricultura familiar, quilombolas, indígenas e assentados da reforma agrária e o Ministério da Agricultura, Pecuária e Abastecimento (MAPA), responsável por atender os grandes e médios produtores agroexportadores. Portanto, dentro do próprio Estado, há dois ministérios que tratam do mesmo tema, mas que pouco dialogam e, muitas vezes, se rivalizam, buscando atender públicos distintos. Outro problema decorre da desproporção de recursos destinados a cada um desses ministérios, já que o MAPA fica com grande parte do montante disponibilizado à agricultura brasileira.

Para o Plano Agrícola e Pecuário 2012-2013 foram disponibilizados R \$ 115,25 bilhões para o MAPA financiar a agricultura empresarial, e somente 17,95 bilhões para o MDA fomentar a agricultura familiar. (MAPA, 2012). Ou seja, o Estado brasileiro continua destinando a maior parte dos seus recursos aos grandes e médios produtores integrados às indústrias e que destinam a sua produção para o mercado externo, em detrimento da agricultura familiar, responsável pela produção de alimentos essenciais a dieta da população.

\section{O fortalecimento das políticas de desenvolvimento rural no Governo Lula}

No início do governo Lula foi criada a Secretaria de Desenvolvimento Territorial, subordinada ao MDA. De acordo com Ortega e Mendonça (2007), o objetivo dessa Secretaria é articular e integrar políticas públicas em nível federal, estadual e municipal com as organizações da sociedade civil, em busca do desenvolvimento de territórios rurais onde há o preomínio da agricultura familiar e dos assentamentos rurais, contribuindo para a elevação das capacidades humanas, institucionais e de autogestão dos territórios.

A principal estratégia da SDT é incentivar ações descentralizadas que buscam valorizar os potenciais endógenos desses territórios. Dessa forma, a abordagem territorial "propiciaria uma maior articulação dos diferentes níveis de governo e das organizações da sociedade em torno de objetivos pactuados" (BRASIL, 2003, apud ORTEGA; MENDONÇA, 2007, p. 116). 
Também no início do governo Lula, foi lançado o Programa Nacional de Desenvolvimento Sustentável de Territórios Rurais (PRONAT), que teve como foco as áreas com maiores níveis de pobreza rural. Os critérios utilizados pela SDT para selecionar os territórios rurais foram os seguintes:

a) Municípios com no máximo $50 \mathrm{mil} / \mathrm{hab}$;

b) densidade demográfica menor de $80 \mathrm{hab} / \mathrm{km}^{2}$;

c) conjunto de municípios pertencentes ao Pronat;

d) Conjunto de municípios que fazem parte do Consad.

Em 2008, foi lançado o Programa Territórios da Cidadania, cujo objetivo é reduzir as desigualdades e combater a pobreza rural. De acordo com Leite e Wesz Junior (2011), o programa Territórios da Cidadania manteve a mesma ideia de território e de abordagem territorial utilizados pelo PRONAT. A diferença é a mobilização de 22 ministérios, a fim de integrar ações e políticas públicas para combater a pobreza e levar cidadania as populações desses territórios. Assim, são incluídos nos recursos aplicados nos TC: bolsa família, Programa Luz para Todos, Pronaf, compra de terras para a reforma agrária, capacitação de produtores rurais e serviços de assistência técnica e extensão rural, construção de farmácias populares, realização de congressos regionais, etc. Os critérios utilizados para a seleção dos territórios da Cidadania foram:

a) baixo índice de desenvolvimento humano - IDH;

b) maior concentração de agricultores familiares e assentados da reforma agrária;

c) maior concentração de população quilombolas e indígenas;

d) maior número de beneficiários do Programa Bolsa Família;

e) maior número de municípios com baixo dinamismo econômico;

f) maior organização coletiva;

g) no mínimo um território por Estado da Federação. (DELGADO; LEITE, 2011).

Até 2009 foram identificados 164 territórios rurais e 120 territórios da cidadania. Conforme Delgado e Leite (2011, p. 94), a "prioridade era atender territórios que apresentassem baixo acesso a serviços básicos, índices de estagnação na geração de renda e carência de políticas integradas e sustentáveis para autonomia econômica de médio prazo".

Dessa forma, com a extinção do Pronaf-InfraEstrutura e Serviços Municipais e a destinação dos recursos para a Secretaria de Desenvolvimento Territorial, os financiamentos repassados aos municípios foram reduzidos, ocasionando a perda de poder das prefeituras e dos CMDRs. Foram constituídos os Colegiados Territoriais, compostos por representantes das três esferas do governo (União, Estado e municípios) e da sociedade civil em cada 
território selecionado pelo programa. Dentre as funções desses Colegiados estão: divulgar ações do programa, identificar as demandas locais, integrar os funcionários públicos e a sociedade, fazer projetos de qualificação e integração de ações e exercer o controle social do programa. (DELGADO; LEITE, 2011).

Segundo Leite e Wesz Júnior (2011), a região Nordeste concentrou $50,7 \%$ dos municípios atendidos pelo Programa Território da Cidadania e $54,6 \%$ de todo o recurso previsto para essa política federal em 2010.

Hespanhol (2010) destaca que tanto nos Territórios Rurais, quanto nos Territórios da Cidadania, há o predomínio de interesses dos segmentos associados à agricultura familiar e aos movimentos sociais. Já setores da sociedade, como representantes do comércio, da indústria e de órgãos gestores (saúde, transporte etc.) não estão participando da implementação desses programas, seja por falta de informação, seja por boicote dos prefeitos e dos executores dos programas. Ainda segundo o autor, a elevada concentração de propriedade da terra e dos meios de produção, o baixo nível de organização social, o comodismo e as arcaicas relações de poder (clientelismo, mandonismo local, populismo) são fatores que dificultam as políticas de desenvolvimento territorial no Brasil.

Assim, os desafios que as políticas de desenvolvimento territorial enfrentam no Brasil são:

- Diversos segmentos da agricultura familiar não estão representados nos colegiados;

- Os colegiados funcionam na maioria das vezes como estruturas burocráticas para o acesso a recursos públicos;

- Privilégios de alguns segmentos em detrimento de outros;

- Em muitos casos a abordagem do desenvolvimento se restringe a projetos setoriais e produtivos;

- As políticas territoriais exluem atores que representam o mercado.

Não obstante os problemas apontados anteriormente, as políticas de desenvolvimento territorial têm tido resultados positivos. A interferência dos prefeitos nos CMDRs foi reduzida e a escala das ações passou de municipal para a intermunicipal, no entanto, a lógica dos investimentos e dos projetos ainda continua restrita ao âmbito municipal e ao setor agropecuário.

Houve uma inovação institucional ao se valorizar a participação dos atores no processo de implementação das políticas públicas. Outro ponto a se destacar foi o reconhecimento jurídico da agricultura familiar como categoria socioprofissional com a Lei $\mathrm{n}^{\circ}$ 11.326, de 24 de Julho de 2006, que estabeleceu as diretrizes para a elaboração da Política Nacional da Agricultura Familiar e Empreendimentos Familiares Rurais. A definição de agricultura familiar 
estabelecida na Lei é bastante ampla, envolvendo diversos segmentos de produtores, desde agricultores pobres até pequenos empresários integrados ao mercado e ao agronegócio.

No início do mandato do governo Lula foi lançado o Programa de Aquisição de Alimentos (PAA), o qual está inserido no Programa Fome Zero. $\mathrm{O}$ PAA busca atender os agricultores familiares que produzem em pequena quantidade e enfrentam dificuldades para a comercialização. Esse programa se enquadrou na política agrária e de segurança alimentar do Governo Lula. De acordo com Veloso (2011, p. 47), o principal objetivo do PAA é combater "a fome e à miséria e a formação de estoques estratégicos, através da compra de alimentos produzidos pelos agricultores familiares sem a necessidade de licitação e, posteriormente, a sua doação para entidades sociais".

Podem participar do PAA os produtores familiares que estejam organizados em organizações coletivas (associações, cooperativas ou grupos com no mínimo cinco pessoas). Esse programa envolve vários ministérios, mas a coordenação é exercida pelo Ministério do Desenvolvimento Social e Combate à Fome, sendo a parte operacional executada pela Companhia Nacional de Abastecimento (CONAB). Para participar dessa política federal é necessário que o produtor tenha a Declaração de Aptidão ao Pronaf - DAP, que é emitido por sindicatos, Casa da Agricultura, CATI. (R. HESPANHOL, 2009).

Uma das modalidades do PAA é a Doação Simultânea, que é operada pela CONAB e têm como objetivo garantir alimentos para as pessoas que estão em condição de miséria e vulnerabilidade alimentar e, simultaneamente, fortalecer a agricultura familiar com a compra de seus produtos. $\mathrm{O}$ limite anual de venda dos produtos pelos agricultores participantes do programa é de $\mathrm{R} \$$ $5.500,00$ por ano e de $\mathrm{R} \$ 6.500$ para o agricultor familiar que faz parte de uma cooperativa. (BRASIL, 2013).

Para R. Hespanhol (2009), o PAA vem beneficiando três atores sociais importantes:

Agricultores Familiares: já que podem comercializar diretamente os seus produtos, com preços mais elevados do que os oferecidos pelos atravessadores e oferece a garantia da venda dos seus produtos até o limite anual de R\$ 5.500,00/ano/produtor;

Instituições assistenciais: recebem alimentos mais saudáveis, diversificados, respeitando os costumes alimentares locais;

Administração Municipal: diminuição dos custos com a aquisição de alimentos fornecidos às instituições assistenciais. 
Em síntese, podemos afirmar que entre as vantagens do PAA para o agricultor familiar destacam-se o incentivo à diversificação produtiva, a garantia de renda e a facilidade de escoamento da produção, além de ser o programa uma boa alternativa aos agricultores descapitalizados e um estímulo ao fortalecimento das organizações coletivas. Veloso (2011) reforça essa ideia, afirmando que o PAA garante a segurança alimentar, ao fornecer produtos de qualidade às instituições, permite uma renda assegurada ao produtor familiar, assim como fortalece o associativismo no meio rural, já que a comercialização deve ser feita por uma organização coletiva.

A partir do ano de 2009 foi criado o Programa Nacional de Alimentação Escolar (PNAE), no âmbito do Fundo Nacional de Desenvolvimento da Educação (FNDE), sendo exigido que pelo menos $30 \%$ do valor repassado às prefeituras municipais para a aquisição de alimentos seja aplicado na compra de alimentos produzidos por agricultores familiares, por intermédio de chamada pública, sem a necessidade de realizar procedimentos licitatórios.

\section{O Programa de Microbacias Hidrográfica como política de desenvolvimento rural em São Paulo}

O Programa Estadual de Microbacias Hidrográficas foi estabelecida no Estado de São Paulo nos anos 1980, mas passou a contar com financiamento do Banco Mundial somente a partir do ano 2000. No período compreendido entre os anos 2000 e 2008 o referido programa contou com o financiamento de US\$ 124.740.200,00, sendo que o Banco Mundial realizou empréstimo de US\$ 55.348.200,00.

Para o acesso ao financiamento externo, o Programa de Microbacias teve que contemplar algumas exigências do Banco Mundial, como a valorização da dimensão ambiental e dos aspectos socioeconômicos dos beneficiários, incentivar a participação dos produtores na elaboração do Plano da Microbacia, descentralizar as ações e ser transparente na aplicação dos recursos.

O principal objetivo do Programa de Microbacias foi aumentar e dar sustentabilidade à produção, produtividade e aprimorar à assistência técnica aos produtores, sobretudo aos pequenos, fomentando o manejo adequado dos recursos naturais, por meio do(a):

(i) - incentivo às práticas modernas de manejo e conservação do solo, água e floresta planejados e implementados na microbacia, envolvendo a comunidade dos produtores; 
(ii) - desenvolvimento da consciência ambiental nas comunidades;

(iii) - ampliação da extensão e do período de cobertura vegetal do solo, protegendo-o dos raios solares e das chuvas intensas de verão;

(iv) - melhoria da estrutura física do solo, elevando a infiltração da água e diminuindo o escoamento superficial;

(v) Elevação da capacidade do Estado em executar, com maior eficiência, um amplo programa de manejo e conservação dos recursos naturais. (SÃO PAULO, 2009).

Dentre as propostas do Programa de Microbacias constavam:

- Conscientizar os agricultores sobre a importância de conservar os recursos naturais;

- Transformar os agricultores e suas famílias em agente do desenvolvimento;

- Criar e/ou fortalecer as associações de produtores;

- Reduzir o uso de agrotóxicos;

- Controlar as erosões;

- Recuperar as áreas degradadas;

- Recompor as Matas Ciliares;

- Proteger os Mananciais e nascentes;

- Readequar as Estradas Rurais. (ANTUNIASSI, 2009).

O foco principal do Programa de Microbacias foi o meio ambiente, que respondeu por seis do total de nove conjunto de ações.

A meta inicial foi atender 1.500 microbacias, abrangendo 90 mil produtores ( $30 \%$ do total do Estado) e 4,5 milhões de hectares. Devido ao atraso no início da operacionalização do PEMH e a diminuição no valor do empréstimo com o Banco Mundial, a meta foi reduzida para 950 microbacias, num total de 2,85 milhões de hectares.

Os municípios que fizessem parte dos EDRs, onde o grau de degradação ambiental fosse maior e tivessem graves problemas socioeconômicos, receberam grande parte dos recursos. Portanto, foram os municípios localizados a Oeste e a Noroeste do Estado de São Paulo, que tiveram maior possibilidade de acesso ao programa.

Os produtores rurais tiveram acesso às práticas individuais, tais como: adubação verde, aquisição de calcário, cerca para proteção de mananciais, terraceamento, faixas de retenção, fossas sépticas biodigestoras, sistema de divisão de pastagens (Kit para cerca e bebedouro), controle de erosão (horas máquinas), aquisição de mudas para reconstituir as matas ciliares, bem como práticas coletivas: edificação de abastecedouros comunitários, aquisição de 
escarificadoresf/subsoladores, de distribuidores de calcário, roçadeiras (costal/tratorizada), semeadoras de plantio direto, kits informática.

Conforme destaca Neves Neto (2009), O Programa de Microbacias teve como principal objetivo atender os pequenos e médios produtores. Já os grandes produtores rurais, por possuírem maior escala de produção, maior facilidade ao crédito e, consequentemente, maior renda, foram menos beneficiados por essa política pública estadual.Não obstante os resultados positivos, como o incentivo ao plantio direto, a adequação de estradas rurais e o plantio de mata ciliar, o Programa de Microbacias teve muitos problemas na sua execução. O principal foi o não cumprimento da maioria das metas inicialmente traçadas.

Outra dificuldade do PEMH foi a abrangência dessa política pública, que beneficiou algumas áreas do Estado de São Paulo (sobretudo o Oeste do Estado), sendo que poucos municípios conseguiram envolver um grande número de produtores.

Dando continuidade as ações desenvolvidas pelo Programa Estadual de Microbacias Hidrográficas (2000-2008), vem sendo implementado no Estado de São Paulo o Projeto de Desenvolvimento Rural Sustentável - Microbacias II - Acesso ao Mercado, que é resultado do acordo (empréstimo 7908-BR) entre o Governo do Estado e o Banco Mundial.

Essa política pública estadual é gerida por duas secretarias, a Secretaria de Agricultura e Abastecimento, por meio da Coordenadoria de Assistência Técnica e Integral (CATI), que é responsável por $81,2 \%$ de todo o recurso disponível para o projeto, e a Secretaria do Meio Ambiente, através da Coordenadoria de Biodiversidade e Recursos Naturais (CBRN).

O objetivo principal do Microbacias II é fomentar o desenvolvimento rural sustentável, gerando oportunidades de emprego e renda, a inclusão social, a manutenção/recuperação dos recursos naturais e a satisfação da comunidade. Para isso, o projeto tem como foco elevar a competitividade da agricultura familiar no Estado de São Paulo. As tribos indígenas e as comunidades quilombolas também são atendidas por essa política pública. (SÃO PAULO, 2010).

Para acessar os recursos do Projeto de Microbacias II, os agricultores familiares e os grupos tradicionais (quilombolas e indígenas) deverão se organizar coletivamente, por meio de associações e/ou cooperativas, buscando uma cadeia produtiva comum.

As metas do projeto são: 
- atender 22.000 famílias de agricultores familiares e 350 famílias de tribos indígenas e 250 comunidades quilombolas;

- 30 mil famílias inseridas nas organizações de produtores receberão assistência técnica e capacitação do programa;

- 1.200 associações/cooperativas de produtores serão identificadas e estimuladas a apresentarem propostas de negócios;

- envolver 550 municípios do Estado de São Paulo, que tenham estabelecido convênio com a SAA/CATI e possuam os Planos Municipais de Desenvolvimento Rural Sustentável elaborados, acompanhados e monitorados;

- Capacitar 550 Conselhos Municipais de Desenvolvimento Rural para que possam elaborar e acompanhar a execução dos Planos Municipais de Desenvolvimento Rural Sustentável;

- Readequar $18.000 \mathrm{~km}$ de estradas rurais em 120 municípios, para permitir a trafegabilidade o ano inteiro;

- Apoiar 40 subprojetos ambientais; e

- Implantar dois programas de serviços ambientais. (SÃO PAULO, 2010).

O Microbacias II - Acesso ao mercado está dividido em três Componentes: 1) Apoio às Iniciativas de Negócios dos Agricultores Familiares; 2) Fortalecimento das Instituições Públicas; e 3) Infraestruturas e Gestão de Projetos. Além dos três componentes, há cinco subcomponentes: 1) Investimento nas Iniciativas de Negócios dos Agricultores Familiares; 2) Fortalecimento das Organizações de Produtores Rurais; 3) Políticas Públicas, Monitoramento de Mercado e Extensão Rural; 4) Fortalecimento da Infraestrutura Municipal; e 5) Sustentabilidade Ambiental.

Apenas os pequenos agricultores familiares inseridos num plano de negócio terão acesso aos incentivos individuais em suas propriedades, sendo que o reembolso concedido pelo programa será de no máximo $70 \%$ do valor do bem ou serviço realizado na propriedade. O limite financeiro do benefício individual, por agricultor, é de 10 mil reais, durante os cinco anos do Projeto.

Os municípios prioritários para a execução do projeto foram selecionados considerando critérios socioeconômicos e ambientais. Para o índice econômico foi levado em consideração a elevada presença de agricultores familiares (LUPA - 2008), a participação do município na totalidade do PIB estadual (SEADE - 2005), a criação de emprego e a composição da renda (FIRJAN - 2005) e o número de associações e/ou cooperativas existentes nos municípios, de acordo com dados do Programa de Microbacias. (SÃO PAULO, 2010). 
O projeto Microbacias II prioriza o atendimento às organizações rurais, que estiverem legalizadas há pelo menos um ano e com no mínimo de 15 associados. Dessa forma, oa parte das organizações rurais ficará de fora do programa, já que não atende aos requisitos exigidos.

Em entrevistas realizadas com técnicos da CATI, diretores de Escritórios Regionais de Desenvolvimento Rural (EDRs) de Dracena e de Araçatuba, com presidentes de associações de produtores rurais (Junqueirópolis, Tupi Paulista e Dracena), engenheiros agrônomos e presidentes de CMDR, muitos ressaltaram a dificuldade de entender os objetivos do programa, apontando as dificuldades na elaboração dos planos de negócios. Também destacaram problemas no excesso de burocracia (documentos exigidos para conseguir o benefício) e que o novo programa favorece os agricultores familiares mais organizados e com maior inserção no mercado.

O engenheiro agrônomo da CATI/Dracena destaca que no "papel" o Projeto Microbacias II é muito bem elaborado, haja vista o foco na geração de renda e nas organizações rurais, porém, na prática, será muito difícil implementá-lo, já que muitas associações de produtores rurais foram criadas apenas para angariar recursos do Programa de Microbacias (2000-2008) e, atualmente, estão inoperantes.

Essa opinião é corroborada pelo presidente da Associação Agrícola de Junqueirópolis, quando aponta a fragilidade da maioria das associações de produtores do Estado de São Paulo e, para ele, o projeto vai priorizar as organizações rurais mais fortalecidas.

Contrapondo a esse argumento, o diretor do EDR de Araçatuba e também um dos elaboradores do novo programa, ressalta que, inicialmente, serão selecionadas as associações/cooperativas mais capitalizadas/organizadas, no entanto, ele espera que as outras organizações se espelhem naquelas e possam ser inseridas no projeto. Isso seria uma aposta difícil de ser concretizada, pois, como destaca Antuniassi (2009) poucas são as organizações coletivas fortalecidas no Estado de São Paulo. A maioria delas funciona apenas no papel, não conseguindo envolver e contar com a participação efetiva dos produtores rurais.

Neves Neto (2009) destaca que na primeira edição do Programa de Microbacias (2000-2008), houve aumento do número de associação criadas e/ou fortalecidas, porém isso ocorreu com o objetivo de acessar os recursos do programa, ou seja, foi um processo de "cima para baixo", fortemente induzido pelo Estado. Após o fim da primeira edição do programa, muitas associações não conseguiram se manter e, atualmente, estão inoperantes, existindo apenas no papel. 
Não obstante a participação da Secretaria do Meio Ambiente, o aspecto econômico predominará no programa, pois a busca por competitividade e o acesso ao mercado serão as chaves-mestras do Microbacias II. A SMA contará com apenas $18,2 \%$ dos recursos e atenderá somente os produtores rurais que estiverem inseridos num plano de negócio aprovado por uma associação ou cooperativa.

Como o projeto não adota a microbacias hidrográfica como unidade de planejamento, fica difícil reflorestar as áreas de preservação permanente de todo um córrego, por exemplo. Assim, se um produtor fizer parte de um plano de negócio, ele terá o direito de utilizar os recursos do projeto para reconstituir sua mata ciliar; no entanto, o seu vizinho, se não fizer parte desse mesmo plano, não será contemplado pelo Microbacias II. Ou seja, o córrego, que perpassa várias propriedades, terá apenas em alguns trechos a sua mata ciliar reconstituída, em outros, continuará sem essa importante vegetação. Há que se ressaltar, no entanto, que a reconstituição vegetal das APPs se constitui numa exigência da legislação e todos os proprietários tenham esta obrigação independentemente de estar ou não inserido num programa governamental.

Outro problema verificado na operacionalização do Microbacias II foi o foco em cadeias produtivas, o que pode levar o produtor rural a se especializar em um único produto, correndo o risco de ficar muito sujeito as oscilações do mercado. Os agricultores familiares melhor sucedidos normalmente diversificam a sua produção, com plantio de milho, feijão, arroz, além de produzem leite, criarem porcos, galinhas, bovinos, produzirem mudas de espécies nativas e exóticas. A diversificação produtiva propicia a ampliação da renda familiar e permite que o agricultor enfrente as vicissitudes do mercado em condições mais favoráveis.

As mais de 450 associações de produtores rurais criadas ou fortalecidas graças a atuação do Programa de Microbacias, em sua primeira edição, terão um papel estratégico na elaboração das propostas de negócios do Microbacias II. (SÃO PAULO, 2009). Dessa forma, de um programa elaborado para todos os produtores rurais das microbacias selecionadas - Programa de Microbacias (2000-2008) - nos municípios, o Projeto Microbacias II restringiu a sua ação aos agricultores familiares integrantes de associações ou cooperativas que submeteram e tiveram os seus planos de negócios aprovados. Ou seja, há uma clara redução no número de participantes e exclusão da maior parte dos agricultores, sobretudo os mais pobres.

Essa redução se refletiu nos primeiros resultados do projeto (primeira chamada pública). Até agosto de 2011 foram apresentadas 134 manifestações de interesse das associações e cooperativas de produtores rurais para iniciativas de negócio ao Microbacias II. No entanto, apenas 32 propostas de negócios 
foram aprovadas pela CATI. Como aponta Neves Neto (2013), esse dado reforça a tese de que o projeto Microbacias II está atendendo poucos produtores de alguns municípios do Estado, em detrimento da maioria. Se fizermos a divisão do número de planos aprovados (32) pelo total de Escritórios de Desenvolvimento Rural do Estado (40), não há sequer um plano aprovado por EDR, o que representa um resultado pouco expressivo.

O maior problema, segundo o diretor do EDR de Araçatuba, foi que a maioria das propostas apresentadas focou muito na produção, deixando de fora a análise do mercado. Além de não terem os planos de negócio aprovados, muitas organizações coletivas podem ter prejuízos financeiros com essa etapa do projeto, já que a maioria delas teve que contratar uma empresa privada para elaborar a proposta de negócio.

A contrapartida de $30 \%$, a ser dada pelas organizações rurais, pode se tornar um problema, conforme relata, em entrevista, o presidente da Associação dos Moradores Santa Rita de Tupi Paulista. Muitas associações não possuem recursos suficientes para arcar com esse encargo e, caso a proposta de negócio não seja aprovada, o custo deverá ser ressarcido pelos associados. A consequência disso poderá ser o endividamento, levando ao seu enfraquecimento ou até mesmo ao encerramento das atividades de muitas associações. (NEVES NETO, 2013).

Como exemplo de organização rural inoperante, podemos apontar a caso do município de Irapuru. Em visita a Casa da Agricultura, o veterinário da prefeitura relatou que a associação de produtores rurais do município, criada para conseguir recursos do Programa de Microbacias, não estava funcionado e os seus maquinários estavam todos quebrados e depositados no prédio da Casa da Agricultura de Irapuru.

Dessa forma, o projeto Microbacias II é altamente seletivo e excludente, por priorizar um grupo pequeno número de produtores (inseridos num plano de negócio) e se restringir a organizações rurais com maior nível de capitalização, as quais normalmente apresentam condições mais favoráveis para enfrentar as vicissitudes do mercado, independentemente do apoio oficial. Novamente, os produtores rurais descapitalizados, que enfrentam graves problemas ambientais em suas propriedades ficarão à margem dessa política pública, financiada com recursos de toda a sociedade.

\section{Considerações finais}

O esgotamento do modelo produtivista baseado na incorporação do pactore tecnológico da revolução verde e no privilégio às políticas setoriais foi duramente questionado pela sociedade tanto no Brasil como em Portugal. Na 
União Europeia, inclusive em Portual, houve o reconhecimento de que os espaços rurais devem ser entendidos não apenas na sua dimensão produtiva vinculada as atividades agropecuárias, mas também nos seus aspectos culturais, ambientais e na possibilidade de explorar toda a sua potencialidade, inclusive por meio da exploração de outras atividades, dentre as quais se destacam aquelas vinculadas ao turismo. Esses aspectos foram incorporados pelo Programa LEADER, no fomento ao desenvolvimento rural em quase todo o território português.

No caso brasileiro, a elevada concentração de renda, a falta de participação da sociedade nas organizações rurais, a deficiente assistência técnica e extensão rural, a baixa instrução das populações rurais e a permanência de estruturas oligárquicas de poder local, impedem a efetivação da maioria das políticas públicas de desenvolvimento rural no Brasil. Ainda predominam as políticas setoriais, a despeito das intenções e da existência de algumas políticas federais de cunho territorial.

O Progama de Microbacias em sua primeira edição inovou ao adotar a microbacia hidrográfica como unidade de análise e ao priorizar a recuperarção dos recursos naturais. No entanto, em sua segunda edição, o programa mudou substancialmente, passando a priorizar as organizações rurais (cooperativas e associações de produtores rurais). Essa mudança de foco do programa, também se refletiu na diminuição no número de agricultores familiares beneficiados.

Assim, tanto no Brasil quanto em Portugal, o Estado reconhece a importância dos espaços rurais e propõe políticas públicas para a dinamização dessas áreas. Porém, a falta de continidade das ações do Programa de Microbacias, no caso de São Paulo e a distribuição desigual dos recursos nos projetos financiados pela iniciativa LEADER/PRODER, ao priorizar as regiões mais desenvolvidas de Portugal, têm dificultado a promoção do desenvolvimento rural.

Conclui-se, portanto, que o acesso da população mais pobre das zonas rurais aos benefícios das políticas públicas é muito mais limitado e isto ocorre tanto no Brasil quanto em Portugal.

\section{Referências}

ABRAMOVAY, Ricardo. Subsídios e Multifuncionalidade na Política Agrícola Européia. Revista de Economia e Sociologia Rural. São Paulo, vol. 40, n², p. 235-264, 2002.

AB'SABER, Aziz. N. Os domínios da natureza no Brasil: potencialidades paisagísticas. São Paulo: Ateliê, 2003. 
ANTUNIASSE, Maria Helena Rocha. Evolução do Processo de Formação, Organização e Atuação das Associações de Pequenos Produtores Rurais - Programa Estadual de Microbacias Hidrográficas. Campinas, Coordenadoria de Assistência Técnica Integral - CATI, 2009.

BAPTISTA, P; FIGUEIREIDO, E. Caminhos possíveis do rural em Portugal: as prioridades do novo programa de desenvolvimento rural. In: Figueireido et al (orgs). $O$ Rural Plural: olhar o presente, imaginar o futuro, Editora 100luz, Castro Verde -PT, 2006, p. 275-290.

BRASIL - Ministério do Desenvolvimento Agrário (MDA). Modalidades do Programa de Aquisição de Alimento (PAA). Disponível em: $<$ http://portal.mda.gov.br/portal/saf/arquivos/view/alimenta-o-escolar/arquivos2012/ModalidadesPAA_quadro.JPG>. Acesso em: 25 jul. 2013.

CARNEIRO, Inês Ferreira. O desenvolvimento Rural em Portugal: dos discursos à prática. In: II Congresso de Estudos Rurais. Sociedade Portuguesa de Estudos Rurais, Universidade dos Açores, Acores-PT, 2004.

CARVALHO, Paulo. Ordenamento Territorial e desenvolvimento. Imprensa da Universidade de Coimbra, Coimbra, 2012.

CAVACO, Carminda. Enquadramento macroeconómico: mudança e crise. in: MEDEIROS, C. A. (dir.) - Geografia de Portugal, Vol. 3 (Actividades Económicas e Espaço Geográfico), Círculo de Leitores, Capítulo 43 Parte I, 2005, . 34-45.

COMISSÃO EUROPEIA. A ABORDAGEM LEADER: Um guia básico, Luxemburgo: Serviço das Publicações Oficiais das Comunidades Europeias, 2006. Disponível em: http://ec.europa.eu/agriculture/publi/fact/leader/2006_pt.pdf, acesso em 08/02/2013.

COVAS, António. Política agrícola e desenvolvimento rural: temas e problemas. Edições Colibri, Lisboa, 2004.

FAVARETO, A. Paradigmas do desenvolvimento rural em questão. São Paulo: Iglu: FAPESP, 2007.

HESPANHOL, A. N. O Desenvolvimento rural na França e no Brasil: as experiências LEADER no centro oeste da Bretanha e do Programa de Microbacias Hidrográficas no Estado de São Paulo. In: V Congresso Europeo CEISAL de latinoamericanistas. Lãs realciones triangulares entre Europa y lãs Américas em el siglo XXI: expectativas y desafios. Bruxelas, 2007.

GONÇALVES NETO, Wenceslau. Estado e Agricultura no Brasil. São Paulo: Hucitec, 1997.

HESPANHOL, A. N. O Programa de microbacias hidrográficas no contexto da agropecuária do Pontal do Paranapanema SP. In: XLVIII Congresso da Sociedade Brasileira de Economia Administração e Sociologia Rural - Campo Grande. SOBER, 2010. v. 1. p. 1-20.

HESPANHOL, A. N. O desenvolvimento rural na França e no Brasil: as experiências LEADER no Centro Oeste da Bretanha e do Programa de Microbacias Hidrograficas 
no Estado de São Paulo. Congresso Europeu de Americanistas-CEISAL, Bruxelas: 2007. http://www.reseau-amerique-latine.fr/ceisal-bruxelles/URB/RUR-2HESPANHOL.pdf

HESPANHOL, R. A. de M. O Programa de Aquisição de Alimentos (PAA) na região de Dracena (SP). In: XLVII CONGRESSO DA SOCIEDADE BRASILEIRA DE ECONOMIA ADMINISTRAÇÃO E SOCIOLOGIA RURAL SOBER. Porto Alegre, 2009.

HOBSBAWN, E. Era dos extremos: o breve século XX; tradução Marcos. Santarrita. São Paulo: Companhia das Letras, 1995.

LEITE, Sérgio P; WESZ JÚNIOR, Waldemar J. O financiamento da política de desenvolvimento territorrial: uma análise do Pronaf e do programa Território da Cidadania. In: Carlos Miranda; Breno Tiburcio. (Org.). Políticas Públicas, Atores Sociais e Desenvolvimento Territorial no Brasil. 1. ed. Brasília, D.F: Instituto Interamericano de Cooperação para a Agricultura (IICA), 2011. v. 1.

MINISTÉRIO DA AGRICULTURA, PECUÁRIA E ABASTECIMENTO (MAPA). Plano Agrícola e Pecuário 2012/2013. Brasilía-DF, 2012. Disponível em: http://www.agricultura.gov.br/arq_editor/file/Politica_Agricola/Plano\%20Agr\%C3\%A Dcola\%202012_2013/PAP2012_release\%20atualizado.pdf, acesso em 15/02/2013.

MORENO, Luís. Novas dinâmicas no espaço rural. In: MEDEIROS, C. A. (dir.) Geografia de Portugal, Vol. 3 (Actividades Económicas e Espaço Geográfico), Círculo de Leitores, Capítulo 43 Parte I, 2005, p. 92-101.

NEVES NETO, Carlos de Castro. O Programa Estadual de Microbacias Hidrográficas em São Paulo: o caso do município de Assis/SP. Dissertação (Mestrado em Geografia). Faculdade de Ciências e Tecnologia, FCT/UNESP, Presidente Prudente. 196 f. 2009.

NEVES NETO, Carlos de Castro. Políticas Públicas \& Desenvolvimento Rural: o Programa de Microbacias I e II no Estado de São Paulo. Tese (doutorado em Geografia). Faculdade de Ciências e Tecnologia, FCT/UNESP, Presidente Prudente, 312 f, 2013.

ORTEGA, Antonio César; MENDONÇA, Nilton César. Estratégias de desenvolvimento territorial rural no Brasil: continuidades e rupturas. In: ORTEGA, Antonio César \& ALMEIDA FILHO, Niemeyer. Desenvolvimento, territorial, segurança alimentar e economia solidária. Campinas-SP: Editora: Alínea, 2007, p. 93121.

ROVER, Oscar José; HENRIQUES, Maria Adosinda. A gestão democrática em debate: O programa LEADER e a sua relação com a sociedade civil local. In: Revista Crítica de Ciências Sociais, 75, Outubro 2006: 117-137.

SÃO PAULO (ESTADO). Secretaria de Agricultura e Abastecimento e Secretaria do Meio Ambiente. Coordenadoria de Assistência Técnica Integral e Coordenadoria da Biodiversidade e Recursos Naturais. Projeto de Desenvolvimento Rural Sustentável. MICROBACIAS II - Acesso ao mercado. Anexo 1: Informações gerais da agropecuária do Estado de São Paulo, 2010 b. 
SÃO PAULO (ESTADO). Secretaria de Agricultura e Abastecimento. Coordenadoria de Assistência Técnica Integral. Informe Final do Programa Estadual de Microbacias Hidrográficas - PEMH (ICR) (BIRD-42380) de um empréstimo no montante de US\$ 55 milhões equivalentes ao Estado de São Paulo para o Programa Estadual de Microbacias Hidrográficas, São Paulo, jan/2009.

SILVA, José Graziano da. O novo rural brasileiro. Campinas: UNICAMP, Instituto de Economia, 1999.

SILVA, José Graziano da. A modernização dolorosa: Estrutura agrária, fronteira agrícola e trabalhadores rurais no Brasil. Rio De Janeiro: Zahar Editores, 1981.

SOUZA, Paulo Cesar. Políticas públicas e desenvolvimento rural na região de Presidente Prudente/SP: PRONAF e PEMH. Tese (doutorado em Geografia). Faculdade de Ciências e Tecnologia, FCT/UNESP, 2012.

VELOSO, Fernando. Políticas Públicas no município de Junqueirópolis (SP): $O$ Pronaf e o PAA. Dissertação (Mestrado em Geografia). Faculdade de Ciências e Tecnologia, FCT/UNESP, Presidente Prudente, 2011.

Carlos de Castro Neves Neto

Mestre e Doutor em Geografia pela FCT/UNESP - Campus de Presidente Prudente-SP.

Atualmente cursa Pós-doutorado em Geografia nessa mesma instituição. Roberto

Simonsen, 305. 19060-900 - P. Prudente, SP.

Email: netosulian@gmail.com

Antonio Nivaldo Hespanhol

Graduado em Geografia pela UNESP - Campus de Presidente Prudente, mestre e doutor em Geografia pela UNESP - Campus de Rio Claro. Realizou estágio de pós-doutorado na Escola de Altos Estudos em Ciências Sociais (EHESS) em Paris-França. É Professor do Departamento de Geografia da UNESP - Campus de Presidente Prudente.

Rua Roberto Simonsen, 305 19060-900 - P. Prudente, SP, Telefone: (18) 3229-5388.

Email: nhespanhol@gmail.com

Recebido para publicação em novembro de 2013

Aprovado para publicação em janeiro de 2014 